\title{
PELATIHAN MEDIA PEMBELAJARAN MULTIMEDIA DENGAN POWERPOINT DAN WONDERSHARE UNTUK PENGEMBANGAN SOFT SKILLS SISWABAGI GURU SD \&TK ${ }^{1}$ )
}

\author{
Budi Setiawan, dan Endro Purnomo \\ Universitas Muhammadiyah Purworejo \\ setiawanbudi75@gmail.com
}

\begin{abstract}
Developmentof soft skills in elementary and kindergarten students can be metthrough alearning model based Multimedia Information Communication Technology (ICT). Training development of multimedia-based instructional media and Information Communication Technology aim stop rovide skills in aking mediaan attractive multimedia learning in a way that isrelativel yeasy. The method applied in this activity is the method of presentation of the introduction of the software includes Microsoft Power Point and Wondershare. Demonstration of the method pengoperasionalisasian program and method of making the practice of instructional media directly by the participants in accord ance with their respective subjects with the use of these programs.
\end{abstract}

Kata kunci : Media Pembelajaran, Guru SD \& TK, Soft Skills, wondershare, power point, multimedia

\section{PENDAHULUAN}

Dunia pendidikan Indonesia dewasa ini dihadapkan pada masalah yang sangat kompleks. Kurangnya sarana pembelajaran, kurangnya kualitas dan kuantitas tenaga pengajar, maupun rendahnya motivasi internal dan eksternal anak sebagai objek pendidikan. Pendidikan sebagai proses yang aktif, dinamik, dan generatif memberikan sumbangan yang penting kepada anak dalam pengembangan soft skill anak seperti pengembangan nalar, berfikir logis, sistematik, kritis, cermat, dan bersikap obyektif serta terbuka dalam menghadapi berbagai permasalahan.

Tercapainya pengembangan soft skill anak dipengaruhi beberapa faktor, antara lain faktor siswa, faktor lingkungan dan faktor guru. Guru sebagai fasilitator dalam pembelajaran, harus senantiasa mengupayakan peningkatan kualitasnya untuk mencapai kemajuan. Penggunaan model pembelajaran konvensional dimana pemahaman siswa lebih banyak dari menghafal konsep yang disampaikan guru akan sangat kesulitan untuk bisa mengembangkan soft skills anak. Pada kondisi terkini, penggunaan media pembelajaran yang tepat untuk pembelajaran di tingkat SD dan TK akan mempengaruhi perkembangan life skill anak.

Media adalah sebuah alat yang mempunyai fungsi menyampaikan pesan. Media pembelajaran adalah sebuah alat yang 
berfungsi untuk menyampaikan pesan pembelajaran. Pembelajaran adalah sebuah proses komunikasi antara pembelajar, pengajar dan bahan ajar. Komunikasi tidak akan berjalan tanpa bantuan sarana penyampai pesan atau media.

Sampai saat ini media pembelajaran multimediaberbasis teknologi informasi dan komunikasi (TIK) belum berkembang dengan optimal di Indonesia. Salah satu kendala pengembangan media pembelajaran multimedia adalah kurang dikuasainya teknologi pengembangan media pembelejaran multimedia berbasis TIK oleh para pengajar, sehingga pengembangan materi pembelajaran multimediaberbasis TIK kurang optimal.

Berdasarkan analisis situasi di atas maka tim pengabdi menyelenggarakan kegiatan pelatihan pembuatan media pembelajaran bagi guru-guru SD dan TK dengan pemanfaatan multimedia pembelajaran berbasis teknologi informasi. Secara khusus dalam pelatihan ini akan dilakukan pelatihan pengembangan presentasi multimedia dengan Microsoft Power Point dan Wondershare game interaktif. Kedua aplikasi ini berkaitan langsung dengan media pembelajaran multimedia. Sedangkan untuk grafis, Microsoft Word dan Excel sebagai pendukung untuk meningkatakan kemampuan guru terutama dalam melaksanakan administrasi pembelajaran.

Microsoft Power Point sangat efektif dan semakin menarik untuk presentasi. Sedangkan aplikasi wonder share sangat menarik dan interaktif untuk mengembangkan game-game atau kuis pembelajran interaktif. Hal lain dalam aplikasi wondershare adalah hasil karya dapat dieksport ke dalam format file SWF, yaitu format file yang digunakan oleh Macromedia Flash sehingga animasi yan dibuat dapat dimainkan di setiap PC yang sudah terinstalasi Flash Player.
Pelatihan yang dikembangkan dan diterapkan ini diharapkan akan memberikan wawasan baru dalam pembuatan media pembelajaran, mengingat kemampuan program ini dalam hal pembuatan animasi untuk media pembelajaran multimedia yang menarik dengan caranya relatif mudah. Dengan dikuasainya media pembelajaran multimedia berbasis multimedia ini diharapkan akan pemicu minat siswa untuk lebih bersemangat dalam mengikuti pelajaran, dan pada akhirnya akan meningkatkan kualitas pembelajaran secara keseluruhan.

\section{METODE PELAKSANAAN PPM}

Ada tiga metode yang diterapkan dalam pelatihan ini, yaitu metode presentasi, metode demonstrasi, dan metode praktik. Metode presentasi diterapkan dalam pengenalan software, kemanfaataannya, dan penerapannya dalam pembuatan media pembelajaran interaktif, Metode Demonstrasi mengenai pengoperasionalisasian program dan Metode Praktik dimana guru-guru mempraktikkan secara langsung pembuatan media pembelajaran sesuai mata pelajaran masing-masing dengan pemanfaatan program Microsoft Power Point dan Wondershare.

Adapun langkah yang telah ditempuh dalam kegiatan PPM ini mencakup beberapa tahap berikut ini.

\section{Persiapan}

Tahap persiapan merupakan tahap awal sebelum pelaksanaan PPM. Dalam tahap ini ada beberapa hal yang dilakukan, yakni Koordinasi Internal, dilakukan oleh Tim untuk merencanakan pelaksanaan secara konseptual, operasional, serta job description masing-masing anggota, penentuan dan rekruitment peserta pelatihan. Dalam perekrutan peserta dipersyaratkan yang telah memiliki kemampuan yang memadai di bidang computer, pembuatan 
Instrumen PPM, seperti lembar presensi, angket, lembar kerja, persiapan konsumsi, publikasi, lokasi, dokumentasi, dan sebagainya.

\section{Pelaksanaan Pelatihan}

Tahap ini merupakan tahap pelatihan yang diberikan kepada para guru SD dan TK Budi Mulia Dua Sedayu. Pelaksanaan pelatihan ini mencakup beberapa hal berikut.

\section{a. Penyajian Materi}

Materi yang disajikan terkait dengan pengenalan dan penggunaan program Microsoft Power Point dan Aplikasi Wondershare untuk pembuatan media pembelajaran. Penyajian ini diploting dalam 6 hari tatap muka. Penyaji materi adalah tim pengabdi sendiri disesuaikan dengan bidang keahlian masing-masing. Materi yang tersajikan sebanyak 4 (empat) bahasan yang masing-masing disajikan oleh anggota Tim Pengabdi sesuai bidang yang bersangkutan. Berikut tabel daftar materi dan pematerinya yang telah terlaksana dalam program PPM ini.

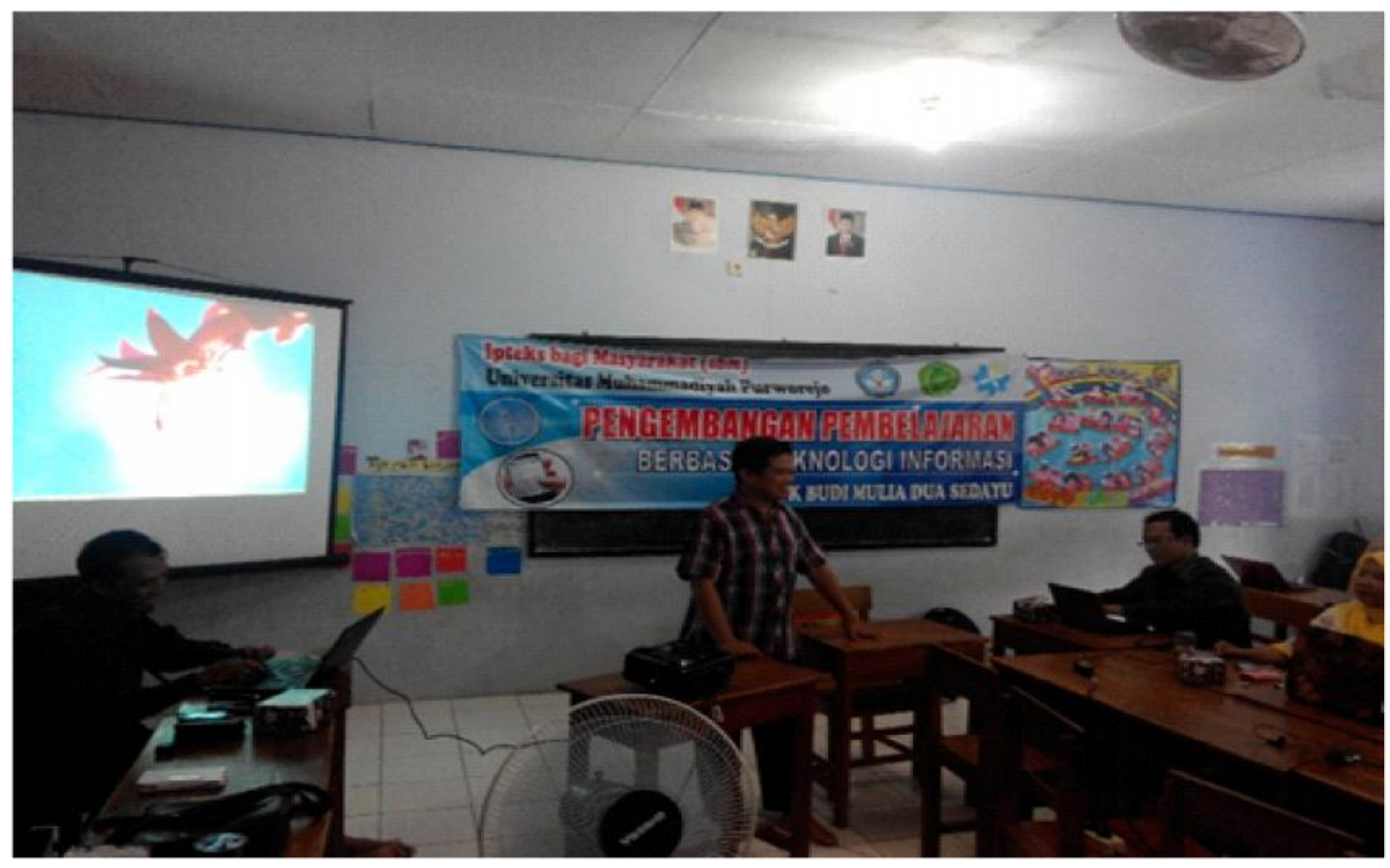

Gambar 1. Ketua Tim Pengabdi memberikan paparan materi 
Tabel 1.

Daftar Jenis Kegiatan, Materi, Pemateri, dan Waktu Pelaksanaannya

\begin{tabular}{|c|c|c|c|}
\hline Jenis Kegiatan & Pokok Bahasan (Materi) & Pemateri & $\begin{array}{c}\text { Waktu } \\
\text { Pelaksanaan }\end{array}$ \\
\hline \multirow[t]{4}{*}{ Teori } & $\begin{array}{l}\text { Pengembangan soft skills } \\
\text { dalam media pembelajaran }\end{array}$ & Budi Setiawan, S.Sos,M.Si & 09 Juni 2014 \\
\hline & $\begin{array}{lcc}\text { Pengenalan } & \text { dan Tips } & \text { Trik } \\
\text { Presentasi } & \text { dengan } & \text { Ms. } \\
\text { Power Point } & & \\
\end{array}$ & Budi Setiawan, S.Sos,M.Si & 09 Juni 2014 \\
\hline & $\begin{array}{l}\text { Pengenalan dan Instalasi } \\
\text { Wondershare }\end{array}$ & Endro Purnomo, S.Kom, M.Cs & 10 Juni 2014 \\
\hline & $\begin{array}{l}\text { Penggunaan Ms. Word dan } \\
\text { Excel untuk menunjang } \\
\text { Pembelajaran }\end{array}$ & M. Sugarindra, S.T., M.T. & 11 Juni 2014 \\
\hline \multirow[t]{3}{*}{ Praktik } & $\begin{array}{lr}\text { Pengembangan media } \\
\text { pembelajaran dengan } \\
\text { Microsof Power Point }\end{array}$ & Budi Setiawan, S.Sos,M.Si & 09 Juni 2014 \\
\hline & $\begin{array}{l}\text { Pengembangan game atau } \\
\text { quiz interaktif dengan } \\
\text { wondershare. }\end{array}$ & Endro Purnomo, S.Kom, M.Cs. & 10 Juni 2014 \\
\hline & $\begin{array}{l}\text { Praktek penggunaan Ms. } \\
\text { Word dan Ms. Excel untuk } \\
\text { menunjang pembelajaran }\end{array}$ & M. Sugarindra, S.T., M.T. & 11 Juni 2014 \\
\hline Pendampingan & $\begin{array}{lr}\text { Pengembangan } & \& \\
\text { Pembuatan } & \text { Materi } \\
\text { Pembelajaran } & \text { Multimedia } \\
\text { berbasis TIK } & \end{array}$ & $\begin{array}{l}\text { Budi Setiawan, S.Sos, M.Si. } \\
\text { Endro Purnomo, S.Kom, M.Cs. }\end{array}$ & Juni-Nopember \\
\hline
\end{tabular}

Pelaksanaan program ini melibatkan mitra dari LKP Bugs Training Center untuk membantu proses pembimbingan dan praktik agar kegiatan dapat berjalan lancar. Kegiatan tanya jawab dilakukan bersamaan dengan penyajian materi. Para peserta dapat langsung berdiskusi dengan para pemateri secara langsung untuk memahamkan materi dan sharing pengalaman terkait dengan masalah yang tengah dibahas dalam materi bersangkutan. 


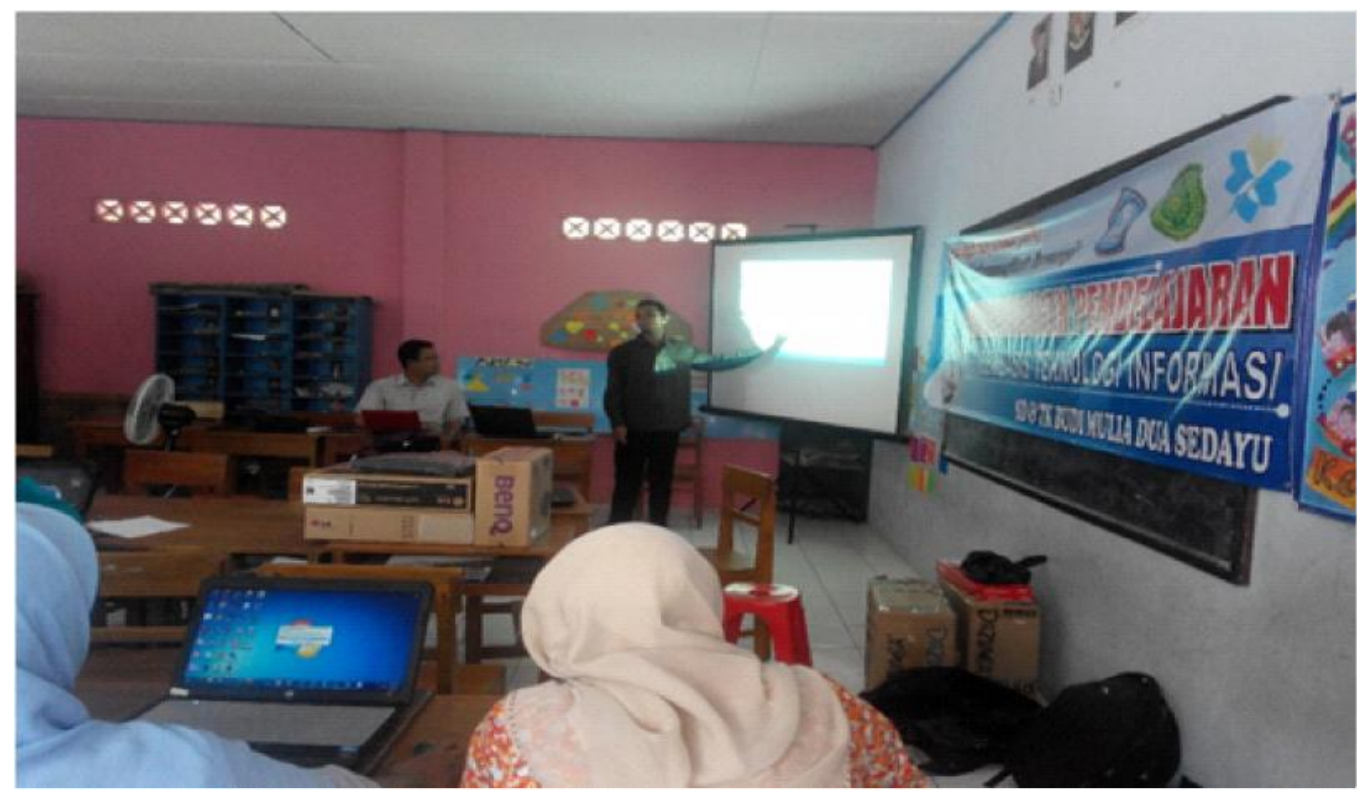

Gambar 2. Pemateri dari LKP Bugs Training Center

\section{b. Penugasan Praktik}

Pada akhir materi peserta diberi tugas praktik sesuai materi yang telah disajikan untuk menggali penyerapan dan pemahaman materi serta melihat kreativitasnya dalam berkarya. Dalam pelatihan ini para guru ditugaskan untuk membuat satu media pembelajaran terkait mata pelajaran yang diampu masing-masing guru. Tim pengabdi mendampingi, memandu dan mengarahkan serta memberikan solusi apabila timbul permasalahan selama penugasan praktik.

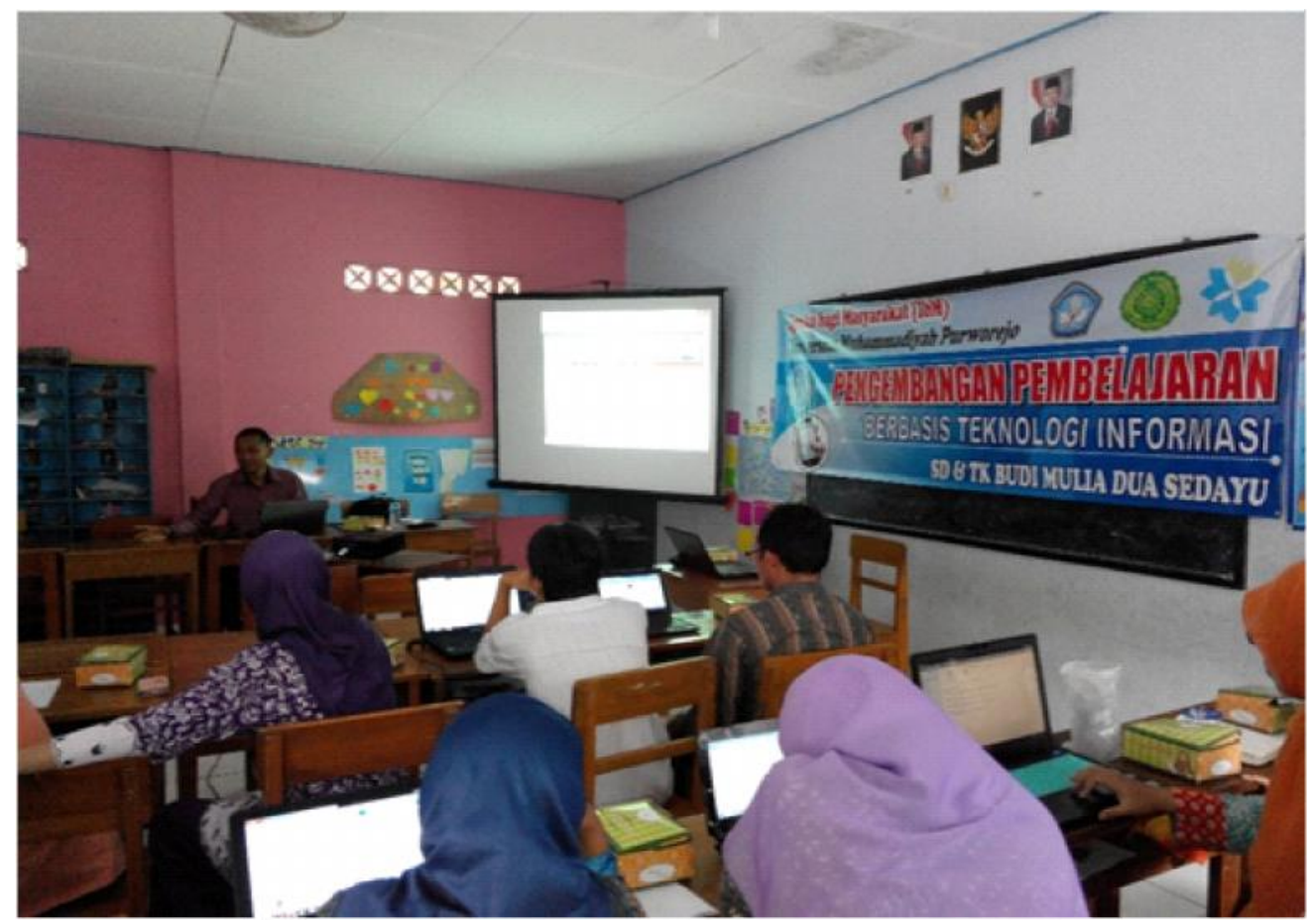

Gambar. 3. Pelatihan Pembuatan Game Interaktif dengan Wondershare 


\section{c. Evaluasi dan Penyempurnaan Karya Media Pembelajaran oleh Tim}

Pada akhir pelatihan, media yang telah dibuat oleh para guru dikumpulkan dan dinilai oleh tim pengabdi kemudian disempurnakan oleh tim untuk kemudian dikembalikan kembali kepada peserta agar dapat digunakan untuk mengajar. Tindakan ini dilakukan mengingat karya media yang dihasilkan para guru masih perlu penyempurnaan, dan tim tim pengabdi ingin agar media pembelajaran betul-betul dapat segera dimanfaatkan untuk mengajar. Tahap selanjutnya tim pengabdi akan melakukan pendampingan dalam pengembangan media pembejaran berbasis multimedia.

\section{d. Refleksi dan Penutupan Program PPM}

Di akhir kegiatan peserta dan Tim melakukan refleksi hasil pelatihan dan para peserta juga memberikan evaluasi akan pelatihan ini. Peserta mendapatkan koreksi dan evaluasi secara langsung terkait hasil karya mereka.

Setelah semua kegiatan yang telah direncanakan terlaksana, ketua tim PPM menutup program dan memberikan pesan kepada segenap peserta pelatihan untuk menerapkan apa yang telah didapatkan untuk memperbaiki media pembelajaran di sekolah masing-masing. Diharapkan pada PPM yang akan akan datang program ini dapat dilanjutkan lagi dan dapat lebih menjangkau jumlah sekolah lain tak hanya SD dan TK Budi Mulia Dua Sedayu saja, sehingga kebermanfaatan program ini dapat dirasakan oleh sekolah yang lebih banyak.

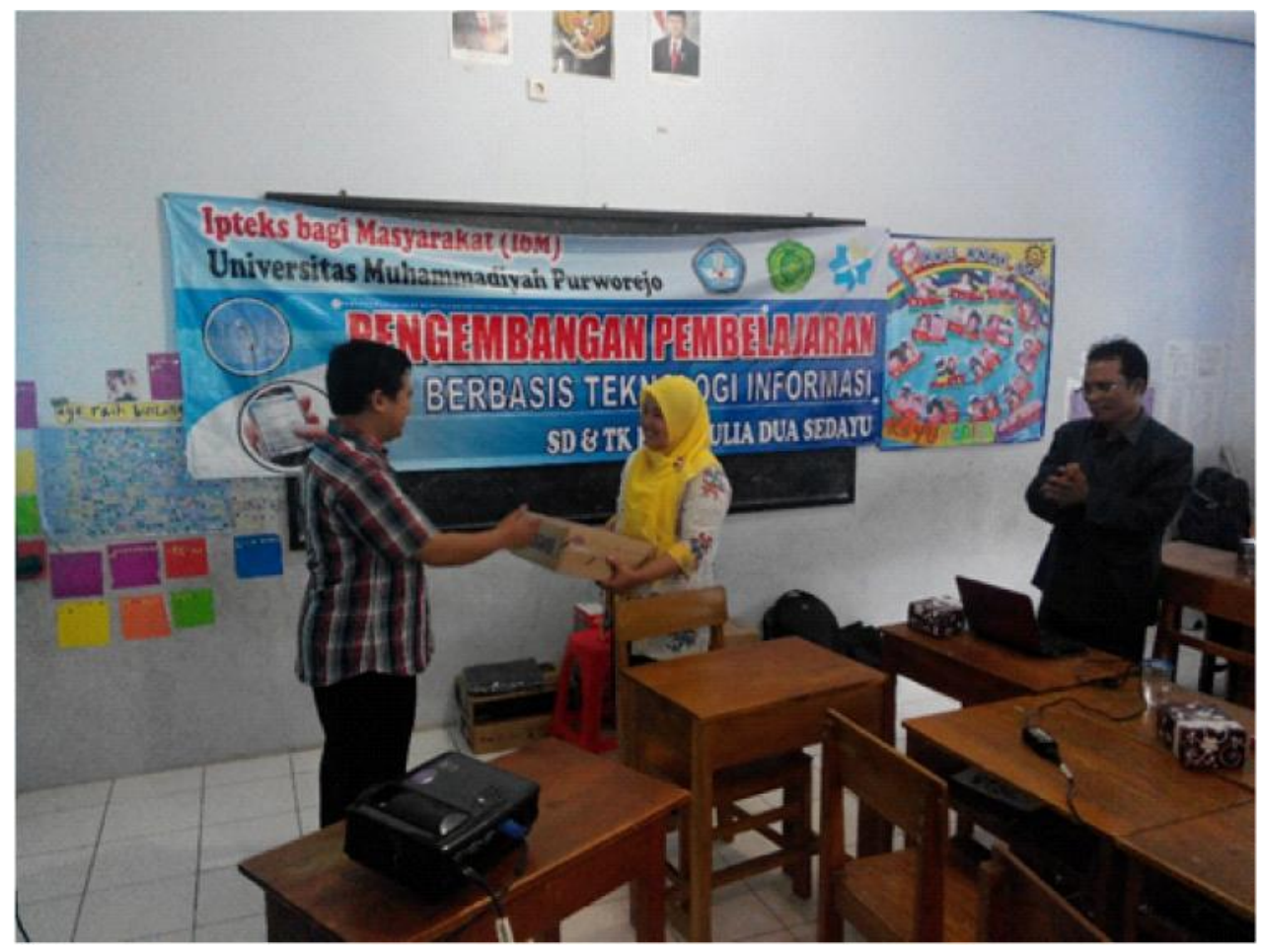

Gambar 4. Ketua Tim memberikan fasilitasi peralatan TIK sebagai motivasi penggunaan pembelajaran multimedia berbasis TIK 


\section{HASIL DAN PEMBAHASAN}

Salah satu komponen yang menentukan mutu dan penggerak pendidikan di Indonesia adalah guru. Namun, tanpa wawasan yang selalu dikembangkan dan di-up grade maka guru akan makin ketinggalan di era sekarang. Apalagi kebutuhan siswa juga makin berkembang seiring dengan lingkungan yang melingkupi siswa. Lebih lagi, pemanfaatan teknologi di kalangan guru masih dianggap memprihatinkan. Kondisi ini dipengaruhi juga oleh kurangnya fasilitas penunjang pengembangan teknologi pembelajaran disamping sumber daya manusia yang menguasai teknologi masih kurang memadai.

Pelatihan ini memberikan beberapa materi yang terkait dengan upaya mengembangkan media pembelajaran interaktif agar pembelajaran yang diberikan oleh guru menjadi lebih atraktif sehingga meningkatkan minat dan kualitas belajar siswa. Materi yang disajikan oleh pengabdi dapat diterima, dicerna, dan dipahami peserta dengan baik. Jumlah peserta yang sebanding dengan jumlah pengabdi yang berperan sebagai instruktur dan tutor menjadikan pelatihan ini menjadi lebih kondusif. Hal ini didukung pula dengan kemampuan peserta di bidang komputer telah cukup memadai karena pada proses perekrutan telah ditetapkan standar minimal peserta harus telah menguasai computer dasar sehingga pelatihan dapat berjalan lancer dan para peserta dapat berkomunikasi dengan para pembicara dan peserta lain dengan lebih baik.

Berdasarkan diskusi yang dilaksanakan setelah pemapatran materi, dapat dilihat bahwa para guru dapat memahami urgensi pengembangan media pembelajaran, mampu mengenal fungsi program Ms. Power Point dan Wondershare, mampu membuat media pembelajaran interktif sesuai dengan bidang/mata pelajaran yang diampu oleh masing-masing guru. Selanjutnya berdasar hasil praktik juga dapat dilihat bahwa para guru mampu mengetahui manfaat program Ms. Power Point dan Wondershare untuk membuat media pembelajaran, mengenal tools Ms. Power Point serta Wondershare dan kegunaannya, Membuat objek shape, menyisipkan Objek Movie dan Sound, membuat Efek animasi, membuat Tombol, dan mampu membuat media pembelajaran interaktif dengan memanfaatkan program Ms. Power Point dan juga membuat quiz interaktif.

Berdasarkan hasil karya media yang dibuat para guru, tim juga membuat lembar evaluasi dan menilai karya para guru dan didapat hasil rata-rata $\mathrm{B}$ (Baik), dan ada dua orang guru yang mendapat nilai SB (sangat baik).

Evaluasi kegiatan dilakukan selama proses kegiatan berlangsung, yaitu pada saat peserta kegiatan melaksanakan proses pembuatan media pembelajaran dengan $M s$. Power Point dan Wondershare. Evaluasi kegiatan PPM ini dilakukan dengan beberapa cara. Evaluasi hasil dilihat dari tugas praktik para peserta yang ada. Hasil praktiknya dinilai dan hal itu menggambarkan keberhasilan materi yang telah disajikan. Selain itu, secara proses juga dicermati kinerja dan kesertaan para peserta. Di akhir kegiatan Tim menjaring data kebermaknaan program pada para peserta. 
Tabel 4.

Lembar Evaluasi

\begin{tabular}{|c|c|c|c|c|c|c|c|c|c|}
\hline \multirow{2}{*}{ No } & \multirow{2}{*}{ Nama Guru } & \multicolumn{6}{|c|}{ Aspek Penilaian } & \multirow{2}{*}{$\begin{array}{l}\text { Hasil } \\
\text { Akhir }\end{array}$} & \multirow{2}{*}{ Skor } \\
\hline & & 1 & 2 & 3 & 4 & 5 & 6 & & \\
\hline 1 & Siti Adriati & 4 & 4 & 3 & 4 & 4 & 4 & 4 & SB \\
\hline 2 & Maya R & 4 & 2 & 3 & 3 & 4 & 3 & 3 & $\mathrm{~B}$ \\
\hline 3 & Israhadi H A & 4 & 4 & 4 & 3 & 3 & 4 & 4 & SB \\
\hline 4 & Yulida T & 4 & 4 & 4 & 4 & 4 & 3 & 4 & SB \\
\hline 5 & Siti Z & 4 & 3 & 4 & 3 & 3 & 3 & 3 & $\mathrm{~B}$ \\
\hline 6 & Afaj P & 4 & 4 & 4 & 4 & 4 & 3 & 4 & SB \\
\hline 7 & Rustini & 4 & 3 & 4 & 3 & 3 & 3 & 3 & $\mathrm{~B}$ \\
\hline 8 & Nunik W & 4 & 3 & 4 & 3 & 4 & 3 & 3 & B \\
\hline 9 & Siti Zubaidah & 4 & 4 & 4 & 3 & 3 & 4 & 4 & SB \\
\hline 10 & Iin Kurniati & 3 & 3 & 3 & 3 & 4 & 3 & 3 & $\mathrm{~B}$ \\
\hline 11 & Murrohmani & 4 & 3 & 4 & 4 & 4 & 4 & 4 & SB \\
\hline 12 & Ngatija & 3 & 4 & 3 & 3 & 3 & 3 & 3 & $\mathrm{~B}$ \\
\hline 13 & Oestam W & 4 & 3 & 3 & 3 & 3 & 4 & 3 & $\mathrm{~B}$ \\
\hline 14 & Puji Ernawati & 4 & 3 & 3 & 3 & 4 & 3 & 3 & $\mathrm{~B}$ \\
\hline 15 & Triyono & 3 & 3 & 4 & 3 & 3 & 4 & 3 & $\mathrm{~B}$ \\
\hline 16 & Sapto K & 3 & 4 & 3 & 4 & 3 & 4 & 3 & $\mathrm{~B}$ \\
\hline 17 & Juniyanto & 4 & 3 & 3 & 3 & 4 & 3 & 3 & $\mathrm{~B}$ \\
\hline 18 & Marlina & 3 & 3 & 3 & 3 & 4 & 3 & 3 & $\mathrm{~B}$ \\
\hline 19 & Efi K & 4 & 3 & 4 & 3 & 3 & 3 & 3 & $\mathrm{~B}$ \\
\hline 20 & Tika NS & 4 & 4 & 4 & 4 & 4 & 4 & 4 & SB \\
\hline & \multicolumn{9}{|c|}{$\begin{array}{l}\text { Keterangan Aspek Penilaian : } \\
\text { 1. Pengenalan Program dan Tools } \\
\text { 2. Pembuatan object shape } \\
\text { 3. Menyisipkan object movie dan sound } \\
\text { 4. Membuat Efek animasi } \\
\text { 5. Membuat tombol } \\
\text { 6. Pembuatan Media Pembelajaran Multimedia Berbasis TIK } \\
\text { Skor: } \\
1 \text { : kurang (K) } \\
2 \text { : cukup (C) } \\
3 \text { : baik (B) } \\
4 \text { : sangat baik (SB) }\end{array}$} \\
\hline
\end{tabular}

Teknik evaluasi dilakukan dengan cara observasi, yaitu melihat bagaimana kualitas karya yang dihasilkan. Melakukan wawancara yaitu memberi berbagai pertanyaan yang terkait dengan pelaksanaan kegiatan baik secara individu maupun secara kelompok. Selain itu, memberi angket untuk mengetahui bagaimana tanggapan peserta tentang pelaksanaan kegiatan pelatihan pembuatan media pembelajaran interaktif dengan pemanfaatan programPower point dan Wondershare yang telah dilaksanakan. Untuk menjaring respon peserta terhadap kebermanfaatan dan kebermaknaan program ini dilakukan evaluasi respon terhadap kegiatan pelatihan. Berikut adalah tabel 
instrumen evaluasi respon peserta terhadap kegiatan pelatihan pembuatan media pembelajaran interaktifdengan pemanfaatan program Power PointdanWondershareguruguru SD \& TK Budi Mulia Dua Sedayu:

Tabel 5.

Instrumen Evaluasi Respon Peserta terhadap Kegiatan Pelatihan

\begin{tabular}{|l|l|l|l|l|l|l|}
\hline No. & \multicolumn{1}{|c|}{ Pernyataan Peserta } & SB & B & S & KB & TB \\
\hline 1. & Kebermanfaatan kegiatan pelatihan & & & & & \\
\hline 2. & $\begin{array}{l}\text { Pelaksanaan kegiatan bagi peningkatan kualitas } \\
\text { media pembelajaran }\end{array}$ & & & & \\
\hline 3. & Pengetahuan tentang operasionalisasi program & & & & & \\
\hline 6. & $\begin{array}{l}\text { Pengetahuan tentang proses pembuatan media } \\
\text { pembelajaran dengan pemanfaatan Program Power } \\
\text { Point dan Wondershare }\end{array}$ & & & & \\
\hline 7. & $\begin{array}{l}\text { Hasil karya yang dihasilkan setelah pelaksanaan } \\
\text { pelatihan }\end{array}$ & & & & \\
\hline
\end{tabular}

Keterangan:

SB : Sangat Baik

B : Baik

S : Sedang

KB : Kurang Baik

TB : Tidak Baik

Angket tersebut dapat disimpulkan bahwa para peserta dapat memperoleh manfaat dari program pelatihan ini untuk meningkatkan kualitas media pembelajaran, mengetahui cara pengoperasionalisasian program Powerpoint dan Wondershare, dan mampu membuat media pembelajaran sesuai dengan mata pelajaran yang diampu masing-masing peserta.

Kegiatan Pengabdian pada Masyarakat ini telah terlaksana dengan baik berkat dukungan berbagai faktor yaitu: Komunikasi antar anggota tim berlangsung lancar dan efektif sehingga koordinasi tim pada proses persiapan, pembagian tugas, pelatihan dan simulasi dapat berlangsung dengan baik dan tepat waktu, peserta pelatihan yang terdiri dari guru-guru TK dan SD Budi Mulia Dua Sedayu sangat antusias dan bersemangat dalam mengikuti pelatihan dari awal hingga akhir. Begitu pula saat penugasan dimana guru-guru tersebut diminta untuk membuat sendiri media pembelajaran sesuai dengan mata pelajaran masing-masing dengan penerapan Powerpoint dan Wondershare, mereka sangat bersemangat untuk bekerja dan bertanya.

Adapun faktor penghambat adalah keterbatasan perangkat laptop atau komputer yang dimiliki atau tersedia di sekolah, sehingga hanya 12perangkat laptop saja yang dapat mendukung pelaksanaan pelatihan ini.

\section{SIMPULAN DAN SARAN}

\section{Simpulan}

Berdasar hasil pelaksanaan kegiatan pengabdian kepada masyarakat ini dan uraian pembahasan di atas, dapat disimpulkan beberapa hal sebagai berikut ini.

a. Pelatihan ini memberikan beberapa materi yang terkait dengan upaya 
meningkatkan kualitas pembelajaran dengan pemberikan pengetahuan mengenai pemanfaatan Program Powerpoint dan Wondershare untuk membuat media pembelajaran multimedia berbasis TIK yang atraktif dan interaktif.

b. Materi yang disajikan dapat diterima, dicerna, dan dipahami peserta dengan baik.

c. Kegiatan berlangsung lancar, tepat waktu dan sesuai dengan yang diharapkan .

\section{Saran}

a. Hendaknya program ini dapat terus berlanjut sehingga lebih banyak lagi sekolah yang dapat merasakan manfaatnya.

b. Para guru peserta pelatihan diharapkan dapat ikut aktif berperan dalam meningkatkan kualitas pembelajaran di sekolah masingmasing dan menularkan ilmu yang diperoleh kepada guru-guru lain di sekolah mereka.

\section{DAFTAR PUSTAKA}

Anderson, Ronald A. 1994. Pemilihan dan Pengembangan Media untuk Pembelajaran, terjemahan oleh Yusufhadi Miarso, dkk. Jakarta: PT. Raja Grafindo Persada.

Arsyad, A. 2002. Media Pembelajaran. PT Raja Grafindo Persada: Jakarta.

Miarso, Yusufhadi. 2004. Menyemai Benih Teknologi Pendidikan. Jakarta: Prenada Media.

Purnomo. 1996. Strategi Pengajaran. Yogyakarta: Universitas Sanata Dharma.

Joyce, Bruce, Marsha, Weil, and Beverly Showers. (1992). Models of Teaching. Boston: Allyn and Bacon.

Mukminan. (1998). Belajar dan Pembelajaran. Yogyakarta: IKIP Yogyakarta.

Muhammad. (2004). Pedoman Pembelajaran Tuntas. Jakarta: Departemen Pendidikan Nasional. Direktorat Jenderal Pendidikan Dasar Menengah. Direktorat Pendidikan Lanjutan Pertama.

Waluya, B. 2006. Multimedia Pembelajaran. Handout perkuliahan Program Magister Program Studi Pendidikan Matematika. UNNES: Semarang. 